\title{
Assessment of learning style preferences of pharmacy students: Findings from public university of Malaysia
}

\author{
Ramadan Mohmed Elkalmi ${ }^{1}$, Abdul Kareem Mohmed Alshami', Akram Ahmad ${ }^{2}$, Muhammad Umair \\ Khan ${ }^{2}$, Norny Syafinaz Ab Rahman ${ }^{1}$ and Ramez Mohmed Alkoudmani ${ }^{1}$ \\ ${ }^{1}$ Department of Pharmacy Practice, Kulliyyah of Pharmacy, International Islamic University Malaysia, Kuantan Campus, Pahang 25200, \\ Malaysia. \\ ${ }^{2}$ Department of Clinical Pharmacy, Faculty of Pharmaceutical Sciences, UCSI University, Cheras-56000, Kuala Lumpur, Malaysia.
}

\begin{abstract}
Background: Student's learning style preference is an important consideration for effective and high quality teaching and learning process. Different teaching approaches may not suit students' preferences, hence, producing a gap between learning and delivery instructions. The aim of this study was to assess the learning style preferences among the first year pharmacy students of public sector university of Malaysia. Methods: A prospective cross sectional study was conducted during non-lecture hour using validated VAK (visual, aural, and kinaesthetic) questionnaire. After a brief description about the study, the questionnaire was distributed to investigate student's learning mode preferences. Results: A total of 118 responses were received, giving a response rate of $100 \%$. Unimodal learning style was preferred by majority of the students $(94.07 \%)$. Specifically, visual approach of learning was commonly reported by the participants (53.4\%), followed by kinaesthetic mode $(22.88 \%)$ and auditory mode $(17.8 \%)$ respectively. Bimodal and tri-modal learning approach was preferred by $5.08 \%$ and $0.85 \%$ patients respectively. Gender, residency, number of siblings and parent's income did not influence learning preferences of pharmacy students indicating no significance association between the factors and learning styles of the students. Conclusion: The study concluded that teaching styles should be adapted to accommodate the preferences of learning styles among pharmacy students to improve the quality of the teaching and learning experiences of pharmacy students.
\end{abstract}

Key words: Learning Styles, Malaysia, Pharmacy, Students, VAK Instrument.

\section{INTRODUCTION}

Learning styles are described as the way the students concentrate, and involve methods in processing and obtaining information, knowledge or experiences. ${ }^{1}$ Learning styles are also referred to strategy and technique used by students in perceiving and processing information. Their achievements would depend on their ability to adapt lessons based on their individual aspects, and teacher created environment to fulfil their needs. ${ }^{2}$ There are many models that describe learning styles or learning preferences. ${ }^{3}$ Even though each model might have their own drawbacks, knowing about learning preferences could help academicians to know more about their students and also can give positive feedback about their learning and approach towards curricula. ${ }^{4}$

Learning styles could be unique to every individual. Therefore it is essential to expose them to different methods of teaching and learning in order to help them to understand the topic in a better way. Teaching and learning styles also vary in terms of age, experience, culture, gender, and level of preparedness..$^{5}$ Many researchers and authors have agreed that individual learning might be influenced hereditary characteristics, but it would eventually change due to environmental features and experiences. ${ }^{6}$
Submission Date : 12-03-2015 Revision Date : :23-04-2015 Accepted Date : :25-05-2015

DOI: 10.5530/ijper.49.4.4 Correspondence Address Dr. Akram Ahmad

Lecturer, Department of ClinicalPharmacy,

Faculty of Pharmaceutical Sciences, UCSIUniversity, Kuala Lumpur, Malaysia E-mail:akrampharma67@ gmail.com

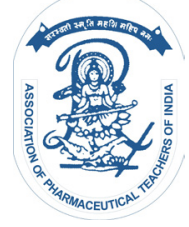

www.ijper.org 
There are many reported tools that could be used to determine learning preferences; one of the most significantly used is VAK instrument. ${ }^{7}$ This instrument was developed by Neil Fleming, an educator in New Zealand, who introduced this concept for evaluation of learning preferences. This learning style classified students into 3 categories of modes. The modes were based on different senses; namely visual (V), auditory (A) and kinaesthetic $(\mathrm{K})$. Categorizing a learning style is essential to identify learner's preferred mode of learning.

International Islamic UniversityMalaysia (IIUM) offers 4 year Bachelor of pharmacy program that leads to registration as a pharmacist. Graduates are expected to have specialized knowledge and skills necessary to meet the standards of pharmacy practice in Malaysia. Critical Judgement, rigorous and independent thinking, self-evaluation and problem solving abilities are some of the skills required by pharmacy graduates. These skills are considered as critical for pharmacist in order to meet the future professional challenges. ${ }^{8}$ The learning style of the students would greatly influence the effectiveness of their learning since pharmacy programmes are relatively difficult and beyond existing perceptions. Many students are unable to identify their own learning style resulting in poor academic performance. Furthermore, several demographic factors such as gender, residency, number of siblings and parents' income might influence learning style preferences. ${ }^{8}$ In view of this, we conducted this study to assess first year pharmacy students' learning style preferences, and to find the association between learning style preferences and factors that influence such preferencces.

\section{MATERIAL AND METHODS}

\section{Study design, participants and settings}

A prospective cross sectional study was conducted on first year pharmacystudents who were enrolled at Kulliyyah of Pharmacy, IIUM Kuantan, Malaysia. A total of 118 students were enrolled in first year of the studied university, and all the participants were approached to participate in this study.

\section{Study instrument}

VAK instrument, developed by Neil Fleming, was used in this study. ${ }^{7}$ This validated instrument has been used by many researchers in past to explore learning style preferences of students. ${ }^{9-11}$ Besides, this instrument has the capability to classify students according to their preferred style of learning. The first category of this instrument is V, which stands for visual. Students with $\mathrm{V}$ type of preference learn best from pictures, graphs and diagrams. They need to use these kinds of symbolic devices to understand the topic in a better way. Meanwhile, the category A stands for auditory, in which the students learn best from discussions, lectures, tutorials and spoken words. The last category is kinaesthetic $(K)$. These students need to do some sort of simulations or practical work to comprehend the topic in the best of ways. Field trips, exhibitions, samples, photographs, case studies, applications, real-life examples are preferred by students belong to this category.

The validated questionnaire of VAK, composed of 30 questions, was used to collect the responses of student towards learning preferences. Three options (A, B and C) were given to the student to mark their responses. Students with many As were considered to have visual preference, while, students with many B's suggest more preferences towards auditory learning style, while the last category, which was kinaesthetic was preferred by students who mostly had chosen $\mathrm{C}$ as their answer. Each possibility represented one of the three modes of perception. Demographic factors such gender, residency, number of siblings, and parents' income were also included in the questionnaire, as they are the influential factors which might affect the students preferences of learning.

\section{Data collection}

The data was collected by the authors responsible for data collection. The data was collected in a separate scheduled session with the intention of not to interrupt any formal scheduled lectures. Before requesting the students for their voluntary contribution in this study, the students were asked whether they had done surveys in determining their learning styles and brief explanation was provided regarding the objectives of this research to facilitate the students in completing the questionnaire. The students were also informed that the completion of the questionnaire would be taken as their consent to participate in this study. Permission of the respective course coordinator was also granted prior to data collection. High level of confidentiality and anonymity was maintained throughout the study period.

\section{Statistical analysis}

The survey data were analyzed using Statistical Package for Social Sciences (SPSS) version 21. The learning preference (i.e., either V, A or K) was identified. The data was reported as the frequency and percentage of students in each category of learning style preferences. In this case, the percentage of students was determined by dividing the number of students who preferred each mode of learning with the total number of respondents. Meanwhile, Chi square tests were conducted to determine any association between independent variables 
(gender, residency, number of siblings, parent income) and dependent variable (learning style preferences). P-value of less than 0.05 was considered as statistically significant.

\section{RESULTS}

A total of 118 questionnaires were returned by the participants, giving the response rate of $100 \%$. The number of females was higher than male students ( $80.5 \%$ vs $19.5 \%$ ). Not much difference was observed between students living in rural and urban area (50.8\% vs $49.2 \%)$. Majority of the participants had 5 or less sibling $(61.9 \%)$. Parental income of majority of the participants was between RM 1000 to RM 5000. The demographic information of the participants is summarized in Table 1.

The results showed that majority of the participants chose one learning style as their preference $(\mathrm{n}=111$, $94.07 \%$ ), while $6(5.08 \%)$ respondents opted bimodal learning styles, and $1(0.85 \%)$ student reported all the multimodal learning styles as preferred ones. Upon investigating, it was explored that those who had unimodal preference, visual style appeared to be the most common learning style $(\mathrm{n}=63,53.4 \%)$ followed by Kinesthetic mode ( $\mathrm{n}=27,22.88 \%)$ and Auditory approach $(\mathrm{n}=21,17.8 \%)$ respectively. Combination of Kinesthetic and auditory style was preferred by $5(4.24 \%)$ participants, and visual and kinesthetic style by $1(0.85 \%)$ participants. No participant reported the blend of visual and auditory approaches as preferred learning style. Multimodal approach (Visual + Auditory + Kinesthetic) was preferred by only single participant $(0.85 \%)$. Learn-

\begin{tabular}{|c|c|c|}
\hline \multicolumn{3}{|c|}{ Table 1: Demographic information of participants } \\
\hline Demographic variables & Frequency & Percentage (\%) \\
\hline Gender & & \\
\hline Male & 23 & 19.5 \\
\hline Female & 95 & 80.5 \\
\hline Residency & & \\
\hline Urban & 58 & 49.1 \\
\hline Rural & 60 & 50.9 \\
\hline Number of siblings & & \\
\hline $0-5$ (Group A) & 75 & 63.5 \\
\hline $6-10$ (Group B) & 40 & 33.9 \\
\hline$>10$ (Group C) & 3 & 2.6 \\
\hline $\begin{array}{c}\text { Parent income (per } \\
\text { month in Ringgit) }\end{array}$ & & \\
\hline$<1000$ (Group A) & 19 & 16.1 \\
\hline $1000-5000$ (Group B) & 35 & 29.7 \\
\hline $5001-10000$ (Group C) & 34 & 28.8 \\
\hline$>10000$ (Group D) & 30 & 25.4 \\
\hline
\end{tabular}

ing style preferences of first year pharmacy students is presented in Table 2.

It was also observed that male participants were more inclined towards kinesthetic style $(39.1 \%)$ of learning as compared to their female counterparts who preferred visual learning style $(58.9 \%)$. Bimodal or multimodal learning styles were not supported by either gender. No significant differences were observed between male and female regarding different styles of learning $(p=0.146)$. Similarly, residential status also appeared to be insignificant $(\mathrm{p}=0.635)$ as preferences of participants was almost similar between both the groups. Although, visual approach was more supported by participant in group A $(53.3 \%)$ and B (50\%) of the sibling variable, a slight variation was observed between the groups as auditory style was the second most preferred choice of group B (35\%), and kinaesthetic style for group A $(24 \%)$. Interestingly none of the participants in group $\mathrm{B}$ preferred bimodal and multimodal learning styles. No significant differences were observed between different groups of the income variable regarding learning style preferences $(p=0.428)$. Majority of the participants in each group preferred visual style of learning, followed by kinesthetic and auditory style. Association of sociodemographic data with learning style preferences is presented in Table 3.

\section{DISCUSSION}

This study aimed to assess first year pharmacy students' learning style preferences. The results suggest that significant proportion of the participants preferred unimodal approach of learning in contrast to other published studies which supported multi-modal styles. ${ }^{12,10}$ Our results are surprising in view of the report that majority of the students are multi-modal in nature. They tend to utilize all their senses in order to grasp all the information processed to them. ${ }^{13}$ However, there are studies which have reported the use of single modality of learning as a preferred style of students. ${ }^{14,15}$ Majority of unimodal learners preferred visual modes of information presentation in this study. The findings somehow differ from previously published studies where kinaesthetic and auditory modes were preferred by the students. ${ }^{10,13,16,17}$ Some researchers have also reported homogenous distribution of students across all the learning style categories. ${ }^{18}$ These results are supported by a literature which suggests that preferred mode of learning is variable in different parts of the world. ${ }^{19}$ However, it is worth discussing the low preference of auditory mode in this study. A traditional lecture is a typical example of auditory mode of learning which supports passive learning and encourages rote memorization. A study 


\section{Table 2: Learning style preferences of participants}

\begin{tabular}{|c|c|c|c|}
\hline Modes & Learning style & Frequency & Percentage (\%) \\
\hline \multirow{3}{*}{ Unimodal } & Visual & 63 & 53.4 \\
\hline & Auditory & 21 & 17.8 \\
\hline & Kinaesthetic & 27 & 22.88 \\
\hline \multicolumn{2}{|r|}{ Total } & 111 & 94.07 \\
\hline \multirow{3}{*}{ Bimodal } & Visual + Kinaesthetic & 1 & 0.85 \\
\hline & Auditory + Kinaesthetic & 5 & 4.24 \\
\hline & Visual + Auditory & - & - \\
\hline \multicolumn{2}{|r|}{ Total } & 6 & 5.08 \\
\hline Multimodal & $\begin{array}{l}\text { Visual + Auditory + } \\
\text { Kinaesthetic }\end{array}$ & 1 & 0.85 \\
\hline \multicolumn{2}{|r|}{ Total } & 118 & 100 \\
\hline
\end{tabular}

\begin{tabular}{|c|c|c|c|c|c|c|c|}
\hline \multirow[b]{2}{*}{ Variable } & \multicolumn{7}{|c|}{ Learning style preferences $\mathrm{N}(\%)$} \\
\hline & $\begin{array}{l}\text { Visual } \\
\text { (V) }\end{array}$ & $\begin{array}{l}\text { Auditory } \\
\text { (A) }\end{array}$ & $\begin{array}{l}\text { Kinaesthetic } \\
\text { (K) }\end{array}$ & VK & AK & VAK & P-value* \\
\hline \multicolumn{8}{|l|}{ Gender } \\
\hline Male & $7(30.4)$ & $5(21.7)$ & $9(39.1)$ & $0(0)$ & $2(8.7)$ & - & \multirow{2}{*}{0.146} \\
\hline Female & $56(58.9)$ & $16(16.8)$ & 18 (18.9) & $1(1)$ & $3(3.1)$ & $1(1)$ & \\
\hline \multicolumn{8}{|l|}{ Residency } \\
\hline Urban & $30(51.7)$ & $8(13.8$ & $15(25.8)$ & $1(1.7)$ & $3(5.1)$ & $1(1.7)$ & \multirow{2}{*}{0.635} \\
\hline Rural & $30(50)$ & $13(21.6)$ & $15(25)$ & $0(0)$ & $2(3.3)$ & $0(0)$ & \\
\hline \multicolumn{8}{|l|}{$\begin{array}{l}\text { Number of } \\
\text { siblings }\end{array}$} \\
\hline 0-5 (Group A) & $40(53.3)$ & $8(10.6)$ & $18(24)$ & $2(2.6)$ & $6(8)$ & $1(1.3)$ & \multirow[b]{2}{*}{0.284} \\
\hline $\begin{array}{c}\text { 6-10 (Group } \\
\text { B) }\end{array}$ & $20(50)$ & $14(35)$ & $6(15)$ & - & - & $1(33.3)$ & \\
\hline $\begin{array}{c}\text { Parent } \\
\text { income (per } \\
\text { month in } \\
\text { Ringgit) }\end{array}$ & $13(11.02)$ & $3(2.54)$ & $2(1.69)$ & - & - & $1(0.84)$ & \multirow{5}{*}{0.428} \\
\hline $\begin{array}{c}<1000 \text { (Group } \\
\text { A) }\end{array}$ & $\begin{array}{c}16 \\
(13.56)\end{array}$ & $8(6.78)$ & $9(7.63)$ & $\begin{array}{c}1 \\
(0.84)\end{array}$ & $1(0.84)$ & - & \\
\hline $\begin{array}{l}1000-5000 \\
\text { (Group B) }\end{array}$ & $\begin{array}{c}15 \\
(12.71)\end{array}$ & 7 (5.93) & $10(8.47)$ & - & 2 & - & \\
\hline $\begin{array}{c}5001-10000 \\
\text { (Group C) }\end{array}$ & 19 (16.1) & $3(2.54)$ & $6(5.08)$ & - & 2 & - & \\
\hline $\begin{array}{l}>10000 \\
\text { (Group D) }\end{array}$ & & & & & & & \\
\hline
\end{tabular}

* derived from chi-square test

conducted in Malaysian schools reported that auditory style was the major preference of the students and a significant relationship was found between overall academic achievement and learning style. ${ }^{20}$ It shows that the learning preference of students change from high school to university. It appears that students at university level are expected to be taught by visual modes of teaching along with diagrams, symbols and image rich power point presentations. More research is required to explore the factors associated with transition of preferences of learning styles of university students.

Studies have expressed the differences in learning behaviour of males and females. However, lack of studies has barred the researchers from establishing such relationship. ${ }^{21}$ In this study no significant difference was observed between males and females in relation to their learning style. These results are in line with other published studies. ${ }^{22}$ It was interpreted from the results 
that kinaesthetic style was most preferred by males than females. It indicates that male students prefer to use their senses, and they favour to get experience through simulations or practicalfor better understanding. This argument is also supported by researchers as they suggest that critical processing strategy is more often associated with males. ${ }^{23}$ In contrast, visual mode was the common choice of female students. The likely reason of this finding is better explained by Rosati by highlighting that female students tend to be more cautious about reading instructions before trying things out. ${ }^{24}$ Males and females are both reported to have preferred single mode of learning style in this study. However, the results are not in accordance to other related studies. ${ }^{16}$

The results revealed that residency factor did not have significant effect on learning preferences of student. In contrast, researchers reported that students from rural area are more likely to engage in dependent learning styles as compared to students from suburban or urban areas. ${ }^{25}$ Similarly, research findings by Sproles ${ }^{26}$ stated that rural students are more committed to, and engaged in the educational process than urban students. The discrepancies in findings might be due to the differences in methodology of the two studies, and unequal population of students from rural and urban region. Students from both the groups have the highest preference in visual learning style, however, urban students showed more preferences towards multimodal approach. Previous studies indicated that selected learning-style preferences, such as auditory instruction, are biological and cannot be changed on demand. ${ }^{27}$ In an attempt to explore the association between learning style and number of siblings, it was noted that learning styles were not influenced by number of siblings. Majority of students from all the groups of sibling variable preferred visual learning style, but variation was observed in the second most common preferred style of the participants between group A and B of the sibling category. It could be due to the reason that participants with more number of siblings may imitate their siblings for learning styles. Additionally, non-homogenous distribution of the participants in each category of this variable may also result in discrepancy in the findings. However, more research is required to establish this relationship. Different studies have been conducted regarding the ability of parents to provide the learning facilities to their children and the effect on their learning style. ${ }^{28}$ Based on the learning style theory, individuals enable to absorb, retain and process new information based on the environment which has been created around them. ${ }^{28}$ It shows that early learning exposure since childhood was very important in determining their learning modalities. Affordability of the parent is considered as an important factor as it is vital for creating learning environment around children. However, no significant relationship was observed between the students having different parental income. Nonetheless, it is essential for the pharmacy educator to identify the learning needs of every student and blend their teaching in way to better facilitate the learning by pharmacy students.

There are several strengths of this study. Firstly, this study has explored an area where not much work has been done on pharmacy students in Malaysia. Secondly, the study was conducted on first year students, which we believe, should be the target participants for such studies as it is the right time for them to identify their learning preferences before they move on to the advanced subjects of pharmacy curriculum. This study would be of great advantage to the students as they could be able to guide themselves on how to process, memorize and understand the information easily and effectively. Thirdly, this study would also give opportunity to pharmacy lecturers to adopt the teaching preference that are tailored with the student's learning style. Fourthly, the findings of this study would encourage the researchers to explore the learning styles of pharmacy students covering other pharmacy schools across Malaysia. Despite of these strengths, the results should be interpreted with cautions as the findings of this single centre, noninterventional study could not be generalizable to the all the pharmacy students in the country. Besides, the questionnaire (VAK) usedis not complete learning style inventory, but it only provided users with a simple profile of their basic sensory learning preferences. It does not take into consideration about other learning criteria in the classroom setting such as engagement, motivation and enthusiasm.

\section{CONCLUSION}

Unimodal, specifically visual (V), was the major preferred learning style of first year pharmacy students participated in this study. No significant difference was observed between the learning preferences of male and female student. Residential status, number of siblings and parental income also did not affect the learning styles of pharmacy students. Pharmacy academicians, at least in the studied university, could utilize these results to adapt to a teaching style in line with students' learning style preference. A nation-wide study is warranted in Malaysia to explore the preferred learning styles of pharmacy students and factors affecting their learning preferences.

\section{ABBREVIATION USED}

VAK: Visual, Aural and Kinaesthetic. 


\section{SUMMARY}

- Student's learning style preference is an important consideration for effective and high quality teaching and learning process.

- Unimodal learning style was preferred by majority of the students $(94.07 \%)$.

- Specifically, visual approach of learning was commonly reported by the participants $(53.4 \%)$, followed by kinaesthetic mode $(22.88 \%)$ and auditory mode $(17.8 \%)$ respectively.

- Bimodal and tri-modal learning approach was preferred by $5.08 \%$ and $0.85 \%$ patients respectively.

- Teaching styles should be adapted to accommodate the preferences of learning styles among pharmacy students to improve the quality of the teaching and learning experiences of pharmacy students.

\section{About Authors}

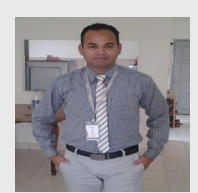

Dr. Akram Ahmad: $\mathrm{He}$ is a pharmacy academic and has taught pharmacy practice \& clinical pharmacy, in leading Private Sector Universities in India and Malaysia. His research programme covers areas related to drug safety, pharmaceutical education, pharmaceutical policy, encompassing access and affordability of medicines, quality use of medicines in community and pharmacoeconomics. He has 50 nos. of journal paper; 5 nos. of abstract; one book. He is a reviewer and editorial board members in several journals of medicine and pharmacy.

\section{REFRENCES}

1. Jantan R, Razali M. Psikologi pendidikan pendekatan kontemporari. Kuala Lumpur: McGraw Hill Education; 2002.

2. Drago WA, Wagner RJ. VARK preferred learning styles and online education. Manag Res News 2004; 27(7): 1-13.

3. Coffield F, Moseley D, Hall E, Eccleston K. Learning styles and pedagogy in post-16 learning: a systematic and critical review. London: Learning Skills and Research Centre; 2004.

4. Miller P. Learning styles: the multimedia of the mind. Educ Resources Inform Center 2001; 451(1): 140.

5. Bertolami CN. Rationalizing the dental curriculum in light of current disease prevalence and patient demand for treatment form vs. content. J Dent Educ. 2001; 65(8): 725-35.

6. Klement M. How do my Students Study? An Analysis of Students' of Educational Disciplines Favorite Learning Styles According to VARK Classification. Procedia-SocBeh Sci. 2014; 132(1): 384-90.

7. Fleming ND. I'm different; not dumb. Modes of presentation (vark) in the tertiary classroom. In: research and development in higher education, edited by zelmer a. Sydney: Proceedings of the 1995 Annual Conference of the Higher Education and Research Development Society of Australasia 1995; 18(1): 308-13

8. Smith L, Saini B, Krass I, Chen T, Bosnic-Anticevich S, Sainsbury E. Pharmacy students' approaches to learning in an Australian university. Am J Pharm Educ. 2007; 71(6): 120.

9. Wehrwein EA, Lujan HL, DiCarlo SE. Gender differences in learning style preferences among undergraduate physiology students. Adv Physiol Educ. 2007; 31(2): 153-7.

10. Lujan HL, DiCarlo SE. First-year medical students prefer multiple learning styles. Adv Physiol Educ. 2006; 30(1): 13-6.

11. Slater J A, Lujan HL, DiCarlo SE. Does gender influence learning style preferences of first-year medical students?. Adv Physiol Educ. 2007; 31(4): 336-42.

12. Urval RP, Kamath A, Ullal S, Shenoy AK, Shenoy N, Udupa LA. Assessment of learning styles of undergraduate medical students using the VARK questionnaire and the influence of sex and academic performance. Adv Physiol Educ. 2014; 38(3): 216-20.

13. Mon AA, Fatini A, Ye CW, Barakat MA, Jen PL, Lin TK. Learning style preferences among pre-clinical medical students. J Med Allied Sci. $2014 ; 4(1): 22-7$
14. Navin R,Suganthi V, Suzanne Maria D'cruz. Learning preferences of students studying Physiology in South India. J Den Med Sci. 2013; 7(1): 15-9.

15. Meechan-Andrews TA. Teaching mode efficiency and learning preferences of first year nursing students. Nur Educ Tod. 2009; 29(1): 24-32.

16. Nuzhat A, Salem RO, Quadri MS, Al-Hamdan N. Learning style preferences of medical students: a single-institute experience from Saudi Arabia. Int J Med Educ. 2011; 2(1): 70-3.

17. Samarakoon L, Fernando T. Learning styles and approaches to learning among medical undergraduates and postgraduates. Rodrigo CBMC Med Educ. 2013; 25(13): 42.

18. Panambur $\mathrm{S}$, Nambiar $\mathrm{V}$, Heming $\mathrm{T}$. Learning Style Preferences of Preclinical Medical Students in Oman. Oman Med J. 2014; 29(6): 461-3.

19. Khanal L, Shah S, Koirala S. Exploration of preferred learning styles in medical education using VARK modal. Russ Open Med J. 2014; 3(1): 0305.

20. Abidin MJZ, Rezaee AA, Abdullah HN, Singh KKB. Learning styles and overall academic achievement in a specific educational system. Int J Human Soc Sci. 2011; 1(10): 143-52

21. Alhajri RA, Counsell $S$, Xiaohui $L$. The influence of multiple human factors on leamer preferences using hypermedia systems. e-Learning, e-Management and e-Services (IC3e) Conference on 2013 IEEE. p. 1-6.

22. James S, D'Amore A, Thomas T. Learning preferences of first year nursing and midwifery students: utilising VARK.Nur Edu Tod. 2011; 31(4): 417-23.

23. Vermunt JD. Relations between student learning patterns and personal and contextual factors and academic performance. Higher Education 2005; 49(3): 205-34

24. Rosati P. Specific differences and similarities in the learning preferences of engineering students. In Frontiers in Education Conference 1999. 29(2): 12C1-7.

25. Hoover TS, Marshall TT. A comparison of learning styles and demographic characteristics of students enrolled in selected animal science courses. J Anim Sci. 1999; 76(12): 3169-73.

26. Cox DE, Sproles EK, Sproles GB. Learning style variations among vocational agriculture students. J Ame Asso Teacher Edu Agri. 1988; 29(1):11-9.

27. Thies AP. The neuropsychology of learning styles. Nat Forum App Edu Res J. 2000; 13(1): 50-62.

28. Mahdjoubi L, Akplotsyi R. The impact of sensory learning modalities on children's sensitivity to sensory cues in the perception of their school environment. J Env Psy. 2012; 32(3): 208-15. 